\title{
Interannual and decadal SST-forced responses of the West African monsoon
}

\author{
Belén Rodríguez-Fonsecal *, Serge Janicot² ${ }^{2}$ Elsa Mohino ${ }^{2,3}$, Teresa Losada', Juergen Bader ${ }^{4}$, Cyril Caminade ${ }^{5}$, \\ Fabrice Chauvin ${ }^{6}$, Bernard Fontaine ${ }^{7}$, Javier García-Serrano', Sebastien Gervois ${ }^{2}$, Mathieu Joly ${ }^{6}$, Irene Polo', \\ Paolo Ruti ${ }^{8}$, Pascal Roucou ${ }^{7}$ and Aurore Voldoire ${ }^{6}$ \\ 'Departamento de Geofisica y Meteorologia, Facultad de Fisicas, Universidad Complutense de Madrid, Spain \\ ${ }^{2}$ LOCEANIIPSL, CNRS, Universite Pierre et Marie Curie, Paris, France \\ ${ }^{3}$ Universidad de Sevilla, Spain \\ ${ }^{4}$ Bjerknes Centre for Climate Research, Bergen, Norway \\ ${ }^{5}$ CERFAX, Tolouse-Cedex, France \\ ${ }^{6}$ GAME/CNRM, Meteo-France/CNRS, Tolouse, France \\ ${ }^{7}$ Centre de Recherches de Climatologie, Université de Bourgogne, Dijon, France \\ ${ }^{8}$ ENEA, Rome, Italy
}

* Correspondence to:

Belén Rodríguez-Fonseca, Universidad Complutense de Madrid, Departamento de Geofísica y Meteorología

Facultad de Fisicas, Avda

Complutense s/n, Madrid 28040,

Spain.

E-mail:brfonsec@fis.ucm.es

Received: 20 February 2010

Revised: 18 September 2010

Accepted: 21 September 2010

\begin{abstract}
We review the studies carried out during the African Monsoon Multidisciplinary Analysis (AMMA)-EU on the changes of interannual sea surface temperature (SST)-West African monsoon (WAM) covariability at multidecadal timescales, together with the influence of global warming (GW). The results obtained in the AMMA-EU suggest the importance of the background state, modulated by natural and anthropogenic variability, in the appearance of different interannual modes. The lack of reliability of current coupled models in giving a realistic assessment for WAM in the future is also stated. Copyright (c) 2011 Royal Meteorological Society
\end{abstract}

Keywords: African Monsoon; decadal variability; interannual variability; Sahelian rainfall; SST forced response

\section{Introduction}

The West African Monsoon (WAM) has experienced a dramatic shift from wetter conditions in the 1950s and 1960s to much drier ones from the 1970s to the 1990s. This drying is one of the strongest interdecadal signals observed during the 20th century at a global scale. Marked interannual rainfall variations in recent decades are superimposed on this decadal drying trend, resulting in extremely dry years with devastating environmental and socio-economic impacts.

Although land surface processes might play a role, oceanic forcing is the dominant driver of the decadal WAM variability (Zeng et al., 1999; Biasutti et al., 2008). The El Niño-Southern Oscillation (ENSO) phenomenon (Janicot et al., 2001), the Atlantic Niño (Giannini et al., 2003) and the Mediterranean sea (Rowell, 2003) have been identified to have an important impact on the WAM system and possibly on its predictability (Ward, 1998) on interannual time scales.

The observed drying trend over the Sahel has been attributed to changes in sea surface temperatures (SSTs). Several studies demonstrated that simulations carried out with a range of atmospheric models using prescribed SSTs were able to reproduce the observed Sahelian rainfall decadal variability (IPCC4). These studies differ in terms of which ocean SSTs are most important: Hoerling et al. (2006) attribute the drying to the interhemispheric gradient in the Atlantic Ocean, whereas Giannini et al. (2003) and Bader and Latif (2003) emphasise the role of the Indian Ocean.

The partial recovery of the Sahel precipitation since the 1990s (Figure 1(a)) could be a response to the increase in greenhouse gases (GHG) through an enhanced land-sea temperature contrast (Paeth and Hense, 2004). Nevertheless, Hoerling et al. (2006) could not detect and attribute a robust GHG-induced signal upon the West African (WA) rainfall recovery, which could instead be induced by the changes in aerosols. Mohino et al. (2010c) show that the tropical Atlantic warming might have caused the 1990s Sahelian rainfall recovery.

Nevertheless, the decadal variability of Sahelian rainfall coincides with other marked shifts like those in global temperature, the Pacific decadal oscillation (PDO), the Atlantic multidecadal oscillation (AMO), and the low-frequency component of the Atlantic Niño (LF ATL3) (Figure 1(a)). These decadal changes affect the background state of the ocean, which can alter the teleconnections between the different interannual SST patterns and the WAM. If this is so, how will the evolution of the background affect the SST-WAM teleconnections? Will it favour some basin, some general situations? Is this predictable at this stage? 


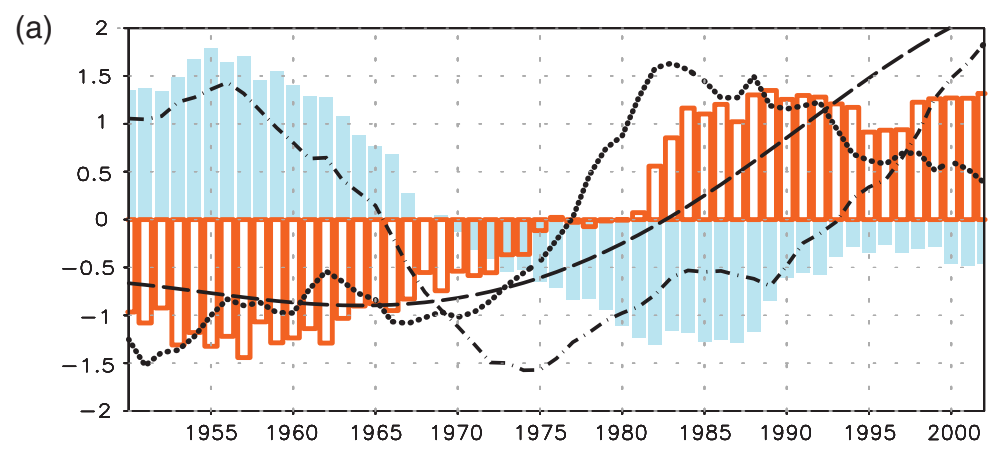

(b)
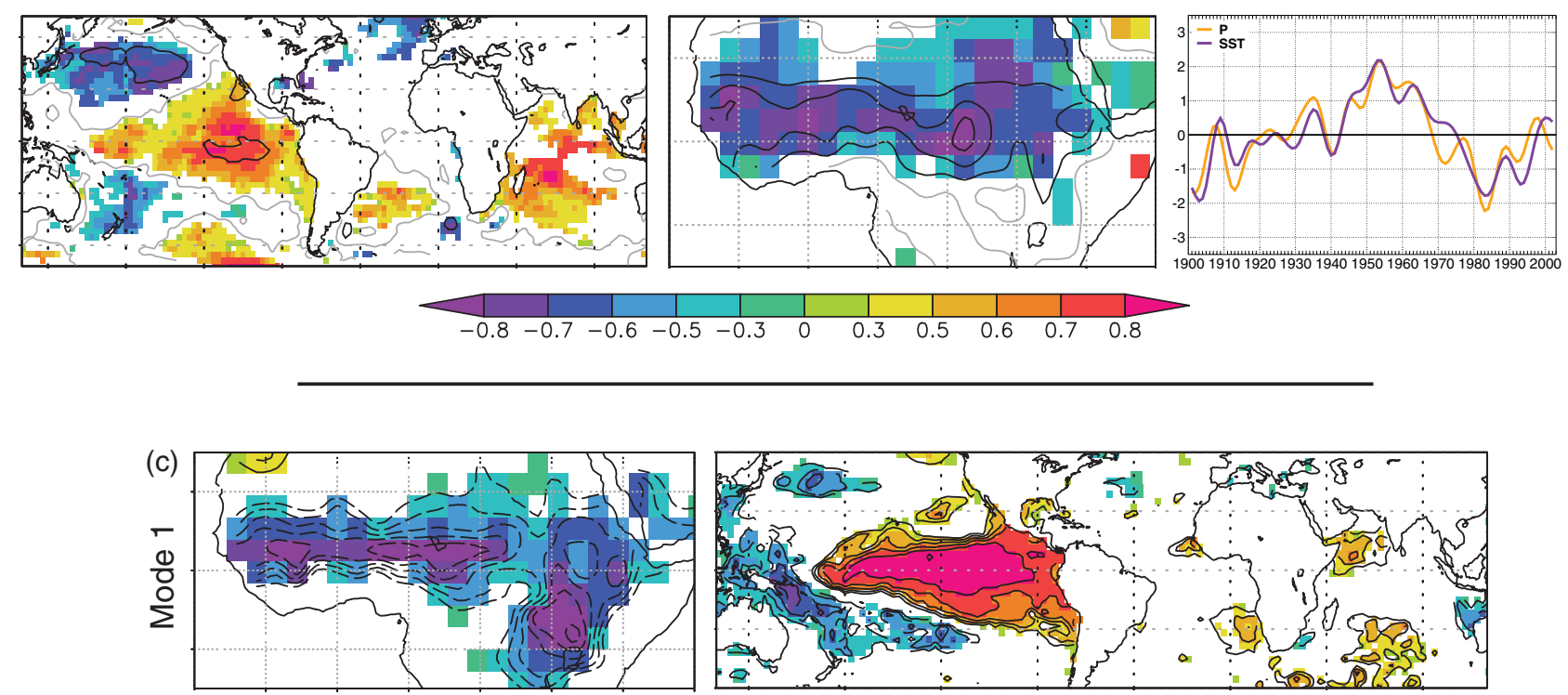

(10)
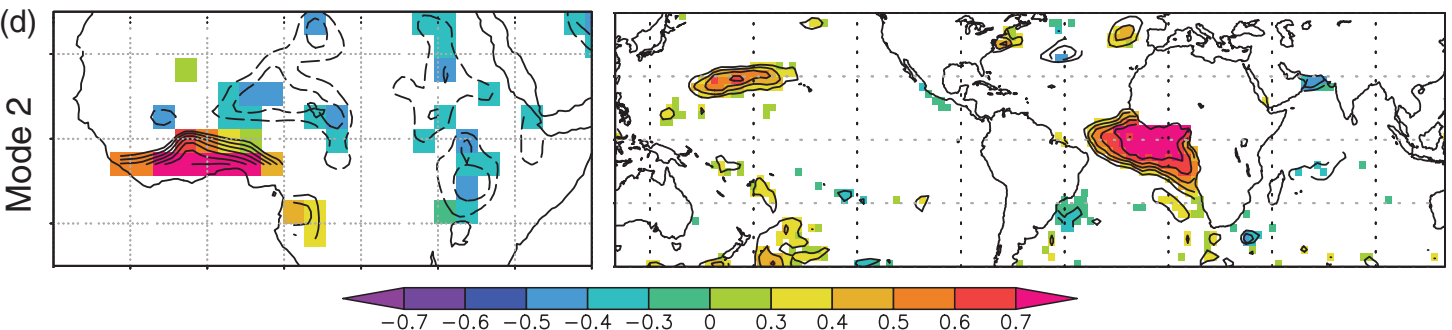

Figure I. (a) Index of II-year running mean Sahel precipitation defined in the $20^{\circ} \mathrm{W}, 20^{\circ} \mathrm{E}-10^{\circ} \mathrm{N}, 20^{\circ} \mathrm{N}$ region using CRUT2.I data (solid bars), 40-year low-pass-filtered (using a ten-order Butterworth filter) global temperature between $45^{\circ} \mathrm{S}$ and $60^{\circ} \mathrm{N}$ (dashed), II-year running mean PDO index (taken from JISAO at http://jisao.washington.edu/pdo/) (dotted), II-year running mean JAS ATL3 index $\left(20^{\circ} \mathrm{W}, 0^{\circ} \mathrm{E}-3^{\circ} \mathrm{S}, 3^{\circ} \mathrm{N}\right)$ (open bars) and AMO (dashed-dotted). All data have been standardised for the period 1950-1998. (b)-(d) Maximum covariance analysis (MCA) of WAM rainfall $\left(0^{\circ}, 20^{\circ} \mathrm{N} ; 20^{\circ} \mathrm{E}, 35^{\circ} \mathrm{W}\right)$ and global SST $\left(60^{\circ} \mathrm{S}, 60^{\circ} \mathrm{N}\right)$, using CRU and HadISST filtered data: (b) first mode of the multidecadal signal, with prior linear detrending the normalised expansion coefficients are also shown; and (c) first mode and (d) second mode of the interannual signal. The correlations significant at the $95 \%$ level are colour shaded (bootstrap procedure) (from Joly et al. (2007) and Joly and Voldoire (2009, 2010)).

A big effort has been made in the African Monsoon Multidisciplinary Analysis (AMMA)-EU project, in order to answer these and other questions about interannual teleconnection patterns between the WAM and global SSTs, as well as the effects of the decadal variability in their modulation, including the role of global warming (GW). Also, it should be taken into account that these results might depend on the observational uncertainty of precipitation. We review the main results obtained and published in the frame of the AMMA-EU project regarding SST-forced signals on WAM at interannual (Section 2.1) and decadal (Section 2.2) time scales.

\section{SST-forced signals on WAM}

Together with observational studies, several atmospheric general circulation model (AGCM) experiments were performed during the AMMA-EU, in order 
to study the role of the different oceanic basins on the WAM variability (Bader and Latif 2009; Fontaine et al., 2009; Losada et al., 2009a, 2009b; Mohino et al., 2010a, 2010b, 2010c; Rodríguez-Fonseca et al., 2010b). The results of coupled models from the Fourth Assessment Report of the Intergovernmental Panel on Climate Change (IPCC AR4) were also analysed with the same aim (Joly et al., 2007; Caminade and Terray, 2009; Joly and Voldoire 2009, 2010). A review of the main findings of these works is shown in the following section.

The results are separated in two main blocks taking into account the low-frequency (decadal and multidecadal) and high-frequency (HF) signals.

\section{I. Interannual variability}

\section{I.I. The Mediterranean}

The first mode of covariability between the post-1979 Mediterranean SSTs and WAM in summer relates a warming over the eastern Mediterranean (eMED) to an increased Sahelian precipitation (Polo et al., 2008; Fontaine et al., 2009; Figure 2(b)). Global SST anomalies associated with this mode show no signal over the tropical oceans. The same analysis carried over the 1957-1978 period shows very limited rainfall anomalies near the Guinean Coast and significant SST anomalies over the tropical Atlantic and Pacific Oceans, suggesting that the Mediterranean pattern could be a fingerprint of a global pattern (Figure 2(a)) for this period.

AGCM simulations, forced with the post-1979 eMED pattern, show that such a warming in the Mediterranean produces the reinforcement of the monsoon southwesterlies, the weakening of the continental northeasterlies, and the northward displacement of the Intertropical Convergence Zone (ITCZ) over West Africa (Fontaine et al., 2009), as shown in Figure 4(a).

\subsubsection{The Tropics}

The leading HF mode of covariability between the Tropics and the WAM relates a Sahelian rainfall reduction with a warming over the tropical Pacific (Joly et al., 2007; Figure 1(c)), in agreement with previous works (Giannini et al., 2003, among others). This relationship is non-stationary, and the Pacific
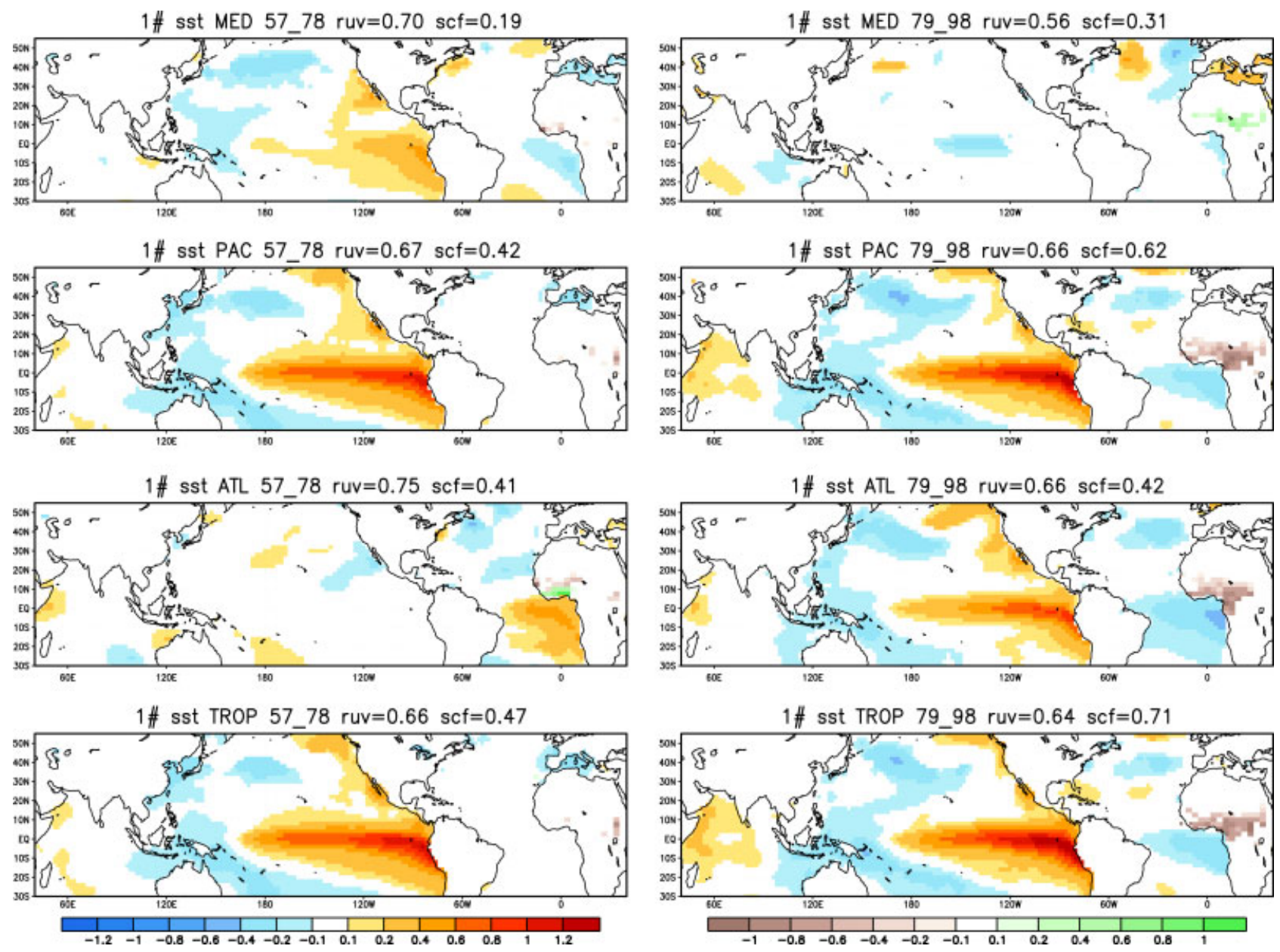

Figure 2. June to September (JJAS) SST and rainfall regression patterns associated with the leading extended maximum covariance analysis (EMCA) mode obtained between (a) and (b) the Mediterranean, (c) and (d) Pacific, (e) and (f) Atlantic, and (g) and (h) global Tropics and the West African rainfall for the period before and after the 1970 s. The squared covariance fraction and SST-rainfall correlation score is indicated at the top of each map. Only regions $95 \%$ statistically significant under a $t$-test are gridded. Right and left colour bars correspond to the rainfall and SST, respectively. 


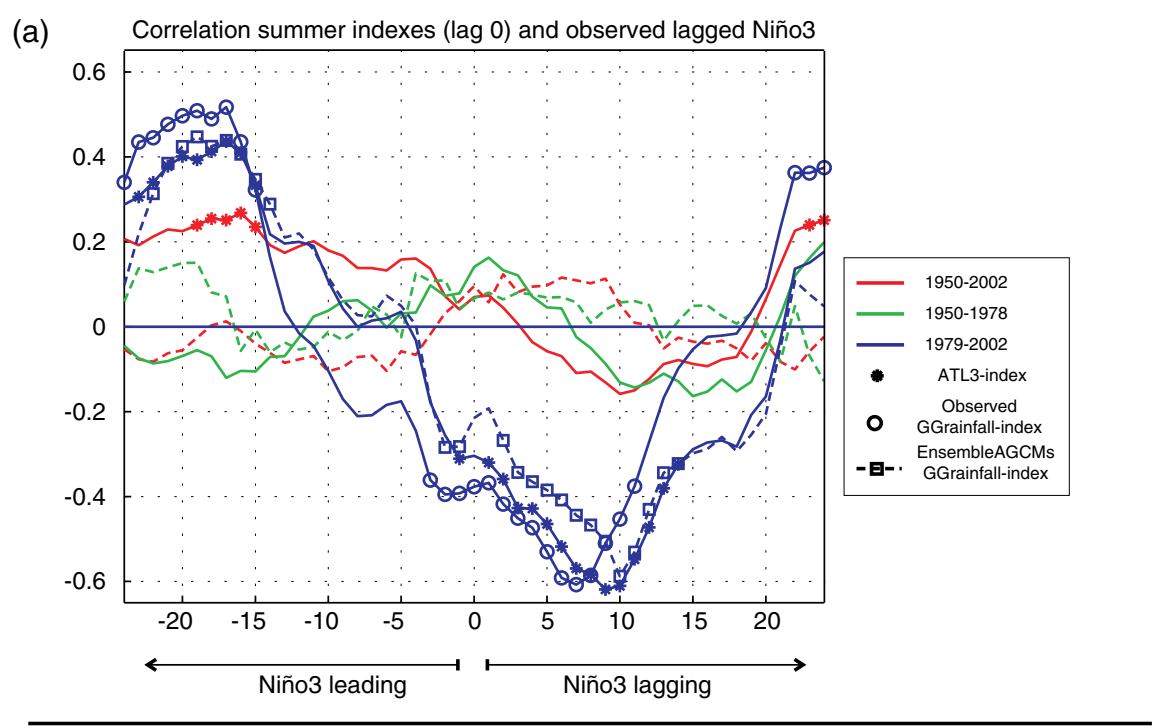

(b)

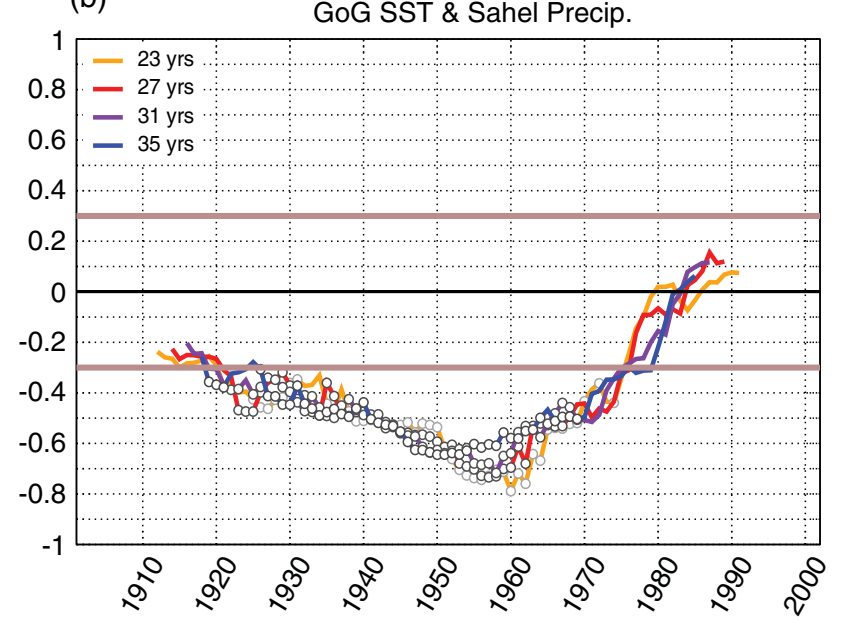

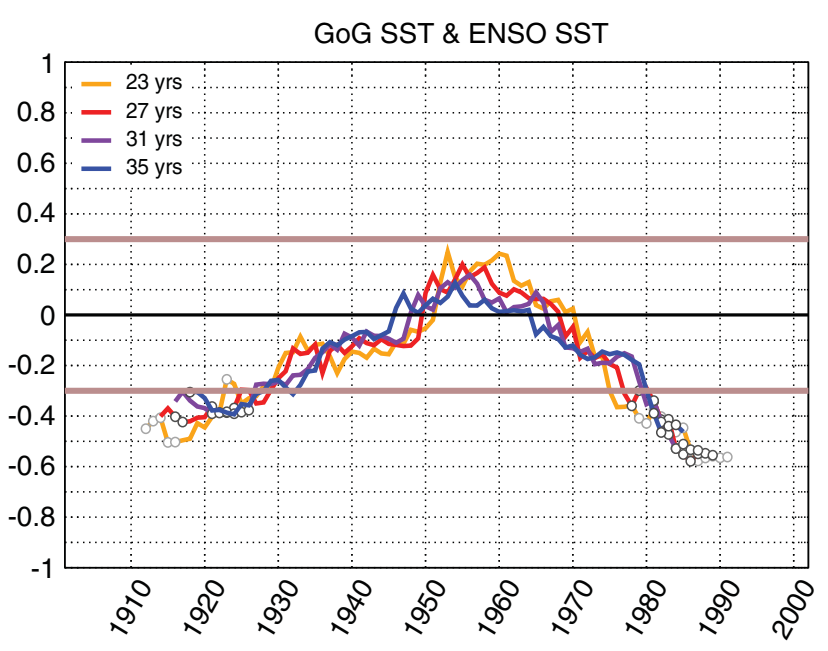

(c) $\quad 30 \mathrm{~N}$ PcP CRU ATL Difs.79-98 minus $57-78$

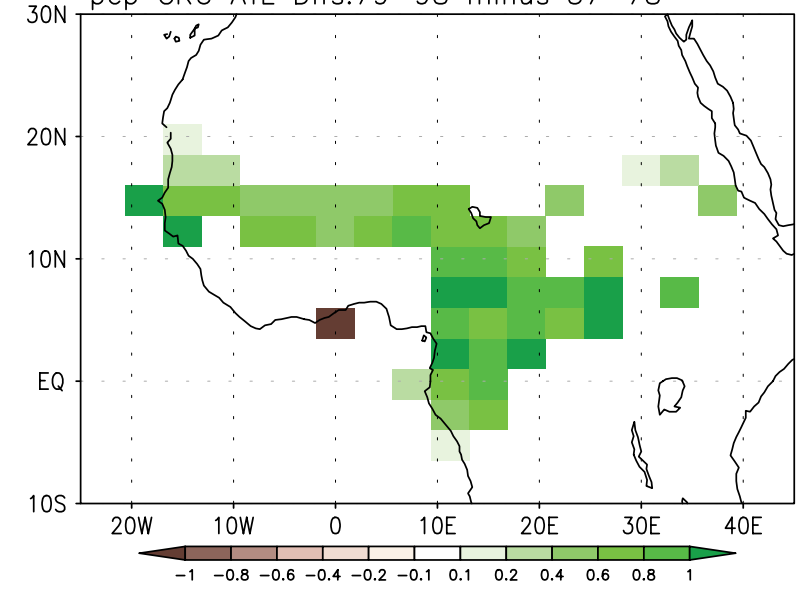

Figure 3. The Atlantic-Pacific connection and its consequences. (a) Correlation coefficient between JJAS ATL3 index and the GG rainfall, and Niño 3 from -20 to +20 months lag, before and after the 1970s. The GG index was calculated with observations (CRU) and the multimodel ensemble of precipitation obtained with the outputs of simulations performed with five AGCMs forced with observed SST (Mohino et al., 20IOb). (b) Running correlations for different window sizes between the GG rainfall and the Sahel precipitation (left) and GG SST and ENSO (right) along the 20th century; circles highlight the $95 \%$ significant values (from Joly and Voldoire, 2010). (c) Difference between the WAM response to the EM before and after the 1970s (from Mohino et al., 20l0b). 
influence increases from the 1970s (Janicot et al., 2001; Figure 2(c)and (d)).

Tropical Pacific AGCM experiments simulate a weak WAM response. The location of the WAM response is tied to the displacement of the associated anomalous convection. In the monsoon pre-onset, a warming over the equatorial Pacific influences the rainfall of the Gulf of Guinea (GG) through anomalous subsidence over the equatorial Atlantic. In the peak and withdrawal of the monsoon, it reduces the Sahel rainfall through equatorial Rossby waves from the maritime continent (Mohino et al., 2010a) by inducing anomalous subsidence over the Sahel (Figure 4(c)).

The observed ENSO-WAM teleconnections generally happen during the development phase/decay of an El Niño/La Niña event. The observed timing of the ENSO-WAM relationship is not correctly simulated in the current Coupled Atmosphere-Ocean General Circulation Models (IPCC AR4) (Joly and Voldoire, 2009; Ruti and Dell'Aquila, 2010).

The second HF covariability mode relates the WAM to the Atlantic Niño/equatorial mode (EM) (Joly et al., 2007; Figure 1(d)). Based on the findings of Polo et al. (2008) and García-Serrano et al. (2008), sensitivity experiments designed by Losada et al. (2009a) showed that the main atmospheric response to a warm summer EM is a weakening of the sea level pressure gradient between the Equator and the Saharan heat low. A southward displacement of the ITCZ/monsoon is the consequence, and leads to a rainfall anomaly dipole between the GG and the Sahel (Figures 2(e) and 4(b)).

Since the 1970s, the observed EM pattern is associated with rainfall anomalies of the same sign in the Sahel and along the GG (Figure 2(f)). Before the 1970s, SST anomalies of the global EM pattern were mainly restricted to the tropical Atlantic. In contrast, after the 1970s positive/negative EM was associated with La Niña-/El Niño-like patterns in the Pacific (Figures 2(f) and 3(a) and (b); Polo et al., 2008; Rodríguez-Fonseca et al., 2009; Wang et al., 2009). The collapse of the correlations between the GG SST and the Sahelian rainfall after the 1970s (Figure 3(b), left) might be due to the counteracting effects of the Pacific and Atlantic basins over the Sahel during these decades (Joly and Voldoire, 2010). Mohino et al. (2010b) confirm this result with observations and SSTforced simulations, showing that the difference in the rainfall response to the Atlantic Niño, before and after the 1970s, appears in the Sahel (Figure 3(c)) and that the difference in the SST mode between both periods appears in the Pacific. Rodríguez-Fonseca et al. (2009) also show, using partial coupled ocean-atmosphere GCM simulations, that the EM is able to determine the phase of the following winter ENSO. Losada et al. (2009b) corroborate the impact of the EM on the Walker circulation and the Indian and Pacific atmospheres since the 1970s.

After the 1970 s, a dominant $(60 \%$ explained variance) mode of covariability exists between the summer WA rainfall and the spring to winter tropical SSTs (Figure 2(h)). A decrease in the WA rainfall is mainly related to the cold SSTs in the GG and maritime continent and warm SSTs in the eastern tropical Pacific and Indian Oceans, and vice versa (Figure 4(d)). Due to the different seasonal SST cycles in the GG and the eastern tropical Pacific and Indian Oceans, the WAM response is mainly tied to the GG SSTs until May. Afterwards the Pacific and Indian SSTs become warm

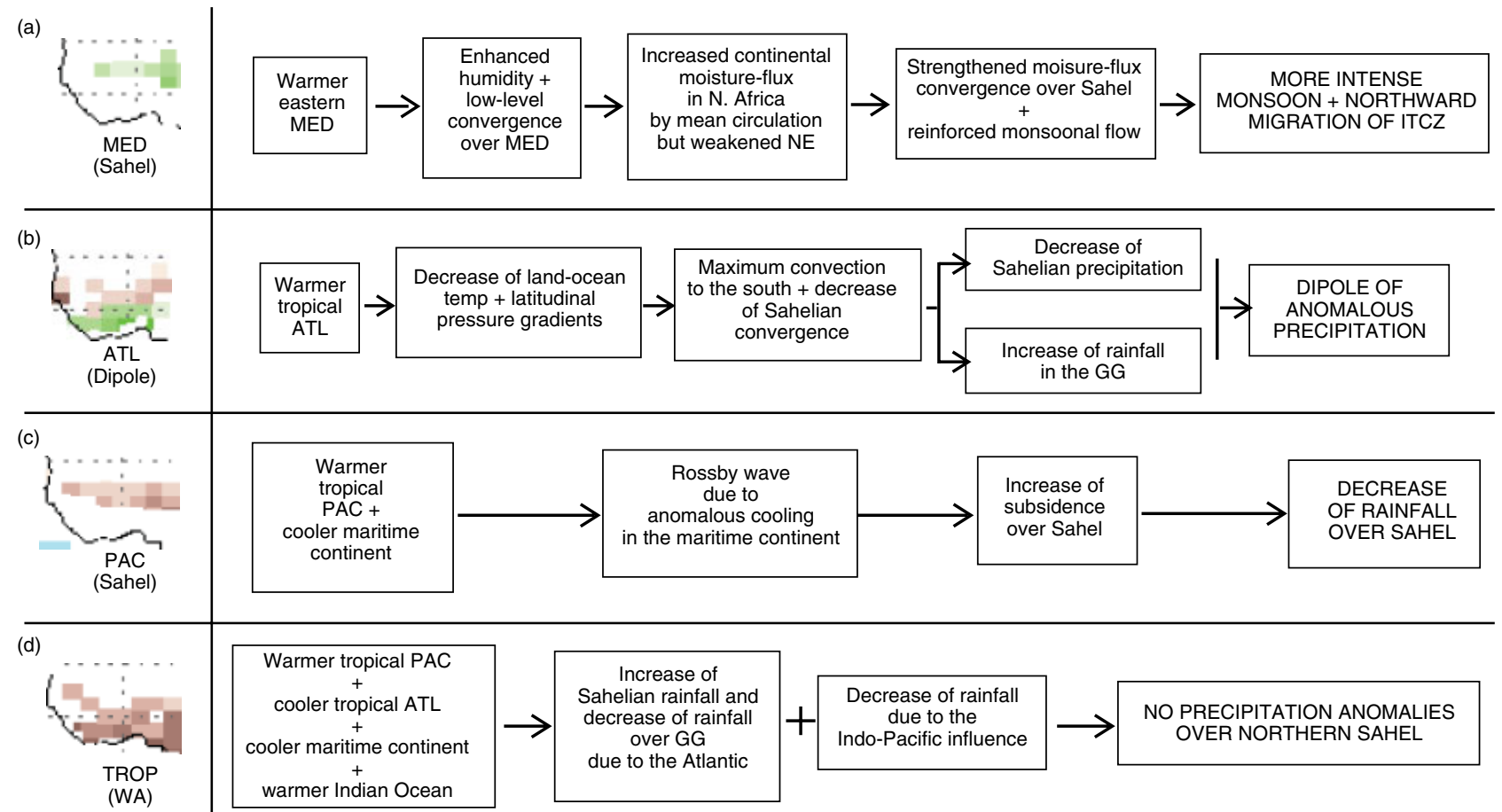

Figure 4. (Left) Observed anomalous rainfall response and (right) flux diagrams explaining the WAM-SST teleconnection mechanisms associated with the (a) Mediterranean, (b) tropical Atlantic, (c) tropical Pacific, and (d) global tropical SST forcings. 
enough to have an additional impact upon the WAM. Bader and Latif (2009) point to the Atlantic and Indian Oceans as the main cause for the 1983 drought over sub-Saharan West Africa, indicating that the Indian Ocean significantly impacts the interannual Sahelian rainfall variability.

In most of the coupled IPCC AR4 simulations, the interannual variability of the Atlantic SST is too weak and its impact on the WAM is hardly reproduced (Joly and Voldoire, 2010). This is due to the general mean biases in coupled GCMs, for which the summer Atlantic cold tongue is not reproduced, leading to warmer SSTs over the GG and to a rainfall overestimation near the coasts. In these coupled simulations, only one model reproduces the observed evolution of the Pacific-Atlantic relationship (Joly et al., 2007).

\subsection{Decadal variability}

Observational studies have shown that the decadal variability of WAM is linked to a global SST interhemispheric pattern. This partly explains the transition between the wet 1950s and 1960s and the dry 1970s and 1980s (Figure 1(a)). Although some have suggested that this pattern could be linked to the anthropogenic forcing, the IPCC AR4 models are unable to accurately reproduce it (Joly et al., 2007).

The first low-frequency mode of covariability between the WAM and global SST relates the WA precipitation to a global pattern (Figure 1(b)), coinciding with Biasutti et al. (2008): a dry Sahel tends to be associated with a warmer tropical region and the interdecadal pacific oscillation (IPO) and AMO patterns over the Pacific and Atlantic Oceans, respectively.

Caminade and Terray (2009) show, using AGCM simulations for the 20th century, that, although the atmospheric internal variability contributes strongly to precipitation over the Sahel at decadal to multidecadal timescales, the simulated drought is also associated with a southward shift of the rain belt over the Sahel, and linked to an interhemispheric SST mode. Their analysis further demonstrates the importance of the tropical Pacific basin in driving the simulated Sahelian rainfall anomalies.

Mohino et al. (2010c) show that the decadal Sahel rainfall variability can be interpreted as the effect of
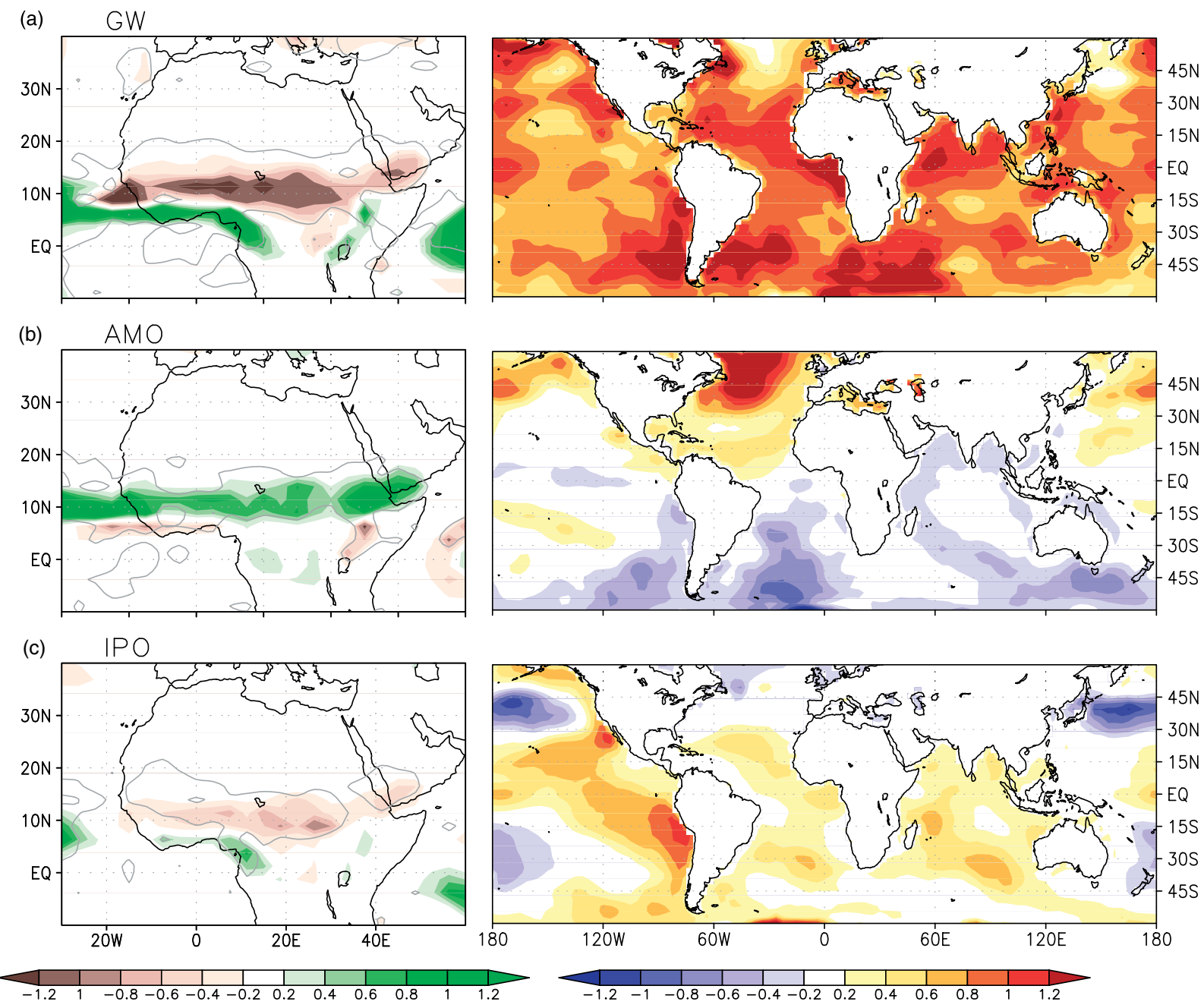

Figure 5. Anomalous precipitation ( $\mathrm{mm} /$ day, left column) simulated by the LMDZ model in response to the anomalous pattern of SST (K, right column) for: (a) GW, (b) AMO, and (c) IPO. The precipitation is the averaged response over the ten-member ensemble simulations. Grey contours mark $95 \%$ significant anomalies according to a $t$-test (from Mohino et al., 20l0c). 
three competing factors, which contribute differently in the interhemispheric SST signature: a multidecadal warming trend of global SSTs $(\mathrm{GW})$, and two patterns of decadal variability, the AMO and the IPO. Their AGCM sensitivity experiments show that the positive phase of GW and IPO patterns lead to a weaker WAM, while a positive AMO leads to an increase in the WAM rainfall (Figure 5). These results indicate that (1) the recent partial recovery of the Sahelian rainfall might be largely explained by the occurrence of a positive AMO phase, (2) the fact that this recovery is weaker than the rainfall amount in the 1950s-1960s, when the AMO was also positive, might be due to the GW forcing which is stronger now than in the 1950s-1960s, (3) in the next $20-30$ years, the GW might be stronger than the AMO (and the AMO could reverse) leading to a new rainfall decrease over West Africa. However, the direct radiative effect of GHG increase on the WAM, not taken into account in this work, could moderate the GW effect.

\section{Discussion and Conclusions}

The work carried out within the AMMA-EU project confirms that the oceanic influence on the Sahelian interannual rainfall variability varies depending on the analysed time period. After the 1970s, a robust mode of covariability between the whole tropical SSTs and WAM has been found. This interannual mode is associated with the disappearance of the dipole of precipitation anomalies between the GG and the Sahel (Figure 4(d)).

The same connection between the tropical ocean basins has been found at the beginning of the 20th century (Joly and Voldoire, 2010), pointing to a multidecadal modulation of this interannual mode (Figure 3(b)). A negative AMO phase, occurring during the 1970s superimposed on the GW signal, could have increased the amplitude of SSTs in the southern tropical Atlantic, and thereby the ability of reaching a deep convection threshold, leading to the Atlantic-Pacific connection. Different background states, superimposed on the interannual signal, could induce different atmospheric responses that would connect or not connect all the tropical regions. These changes in the interannual variability, modulated by the decadal variations of the background state, would, in turn, affect the WAM response to SST forcing. Other numerical experiments are required to further confirm these hypotheses.

The superposition of the different low-frequency SST signals could be responsible for the decadal trend of the Sahelian rainfall. Since the 1970s, the Sahelian rainfall could have decreased due to both the AMO and the GW SST modes (Mohino et al., 2010c). The change in the AMO phase at the end of the 20th century could have led to the partial recovery of the precipitation.
Coupled models used for the IPCC AR4 are unable to accurately simulate the main SST-WAM teleconnections, both at interannual and decadal scales. They also fail in simulating the tropical Atlantic climate: they are not able to reproduce the inland penetration of the rain belt over West Africa. Thus, the EM and the Atlantic-Pacific connections are not reproduced. Because of the simplification of different aspects of the climate system and of persistent biases, the simulated effects of the SST on the monsoon are just hypothetical. This is a very critical issue for the confidence of the climate change scenarios over West Africa and for the decadal scale forecasting planned for the next IPCC AR5 exercise. The tropical Atlantic bias is a hot spot to be resolved in the near future.

\section{Acknowledgements}

This study was part of the African Monsoon Multidisciplinary Analysis (AMMA) project (http://www.amma-international. org). The support of the AMMA project is gratefully acknowledged (see http://onlinelibrary.wiley.com/doi/10.1002/asl.331/ full for full acknowledgement).

\section{References}

Bader J, Latif M. 2003. The impact of decadal-scale Indian Ocean sea surface temperature anomalies on Sahelian rainfall and the north Atlantic oscillation. Geophysical Research Letters 30(22): 2169. DOI: 10.1029/2003GL018426.

Bader J, Latif M. 2009. The 1983 drought in the West Sahel: a case study. Climate Dynamics. DOI: 10.1007/s00382-009-0700-y.

Biasutti M, Held IM, Sobel AH, Giannini A. 2008. SST forcings and Sahel rainfall variability in simulations of the twentieth and twentyfirst centuries. Journal of Climate 21: 3471-3486.

Caminade C, Terray L. 2009. Twentieth century Sahel rainfall variability as simulated by the ARPEGE AGCM, and future changes. Climate Dynamics 35: 75-94. DOI: 10.1007/s00382-009-0545-4.

Fontaine B, García-Serrano J, Roucou P, Rodríguez-Fonseca B, Losada T, Chauvin F, Gervois S, Sivarajan S, Ruti P, Janicot S. 2009. Impacts of warm and cold situations in the Mediterranean Basins on the West African monsoon: observed connection patterns (1979-2006) and climate simulations. Climate Dynamics 35: 95-114. DOI: 10.1007/s00382-009-0599-3.

García-Serrano J, Losada T, Rodríguez-Fonseca B, Polo I. 2008. Tropical Atlantic variability modes (1979-2001). Part II: timeevolving atmospheric circulation related to SST-forced tropical convection. Journal of Climate 21: 6476-6497.

Giannini A, Saravanan R, Chang P. 2003. Oceanic forcing of Sahel rainfall on interannual to interdecadal time scales. Science 302: 1027-1030.

Hoerling MP, Hurrell JW, Eischeid J. 2006. Detection and attribution of 20th century Northern and Southern African monsoon change. Journal of Climate 19: 3989-4008.

Janicot S, Trzaska S, Poccard I. 2001. Summer Sahel-ENSO teleconnection and decadal time scale SST variations. Climate Dynamics 18: $303-320$.

Joly M, Voldoire A. 2009. Influence of ENSO on the West African monsoon: temporal aspects and atmospheric processes. Journal of Climate 22: 3193-3210.

Joly M, Voldoire A. 2010. Role of the Gulf of Guinea in the interannual variability of the West African monsoon: what do we learn from CMIP3 coupled simulations? International Journal of Climatology 30: 1843-1856. DOI: 10.1002/joc.2026. 
Joly M, Voldoire A, Douville H, Terray P, Royer J-F. 2007. African monsoon teleconnections with tropical SSTs: validation and evolution in a set of IPCC4 simulations. Climate Dynamics 29: 1-20.

Losada T, Rodríguez-Fonseca B, Janicot S, Gervois S, Chauvin F, Ruti P. 2009a. A multimodel approach to the Atlantic ecuatorial mode. Impact on the West African monsoon. Climate Dynamics 35: 29-43. DOI: 10.1007/s00382-009-0625-5.

Losada T, Rodríguez-Fonseca B, Polo I, Janicot S, Gervois S, Chauvin F, Ruti P. 2009b. Tropical response to the equatorial mode: AGCM multimodel approach. Climate Dynamics 35: 45-52. DOI: 10.1007/s00382-009-0624-6.

Mohino EB, Rodríguez-Fonseca B, Mechoso CR, Gervois S, Ruti P, Chauvin F. 2010a. West Africa Monsoon response to Tropical Pacific sea surface anomalies. Journal of Climate (submitted).

Mohino EB, Rodríguez-Fonseca B, Losada T, Gervois S, Janicot S, Bader J, Ruti P, Chauvin F. 2010b. Changes in the inter-annual West African rainfall modes. Climate Dynamics (submitted).

Mohino E, Janicot S, Bader J. 2010c. Sahelian rainfall and decadal to multidecadal SST variability. Climate Dynamics. DOI: 10.1007/s00382-010-0867-2

Paeth H, Hense A. 2004. SST versus climate change signals in West African rainfall: 20th-century variations and future projections. Journal of Climate Change 65: 179-208.
Polo I, Rodríguez-Fonseca B, Losada T, García-Serrano J. 2008. Tropical Atlantic variability modes (1979-2002). Part I: timeevolving SST modes related to West African rainfall. Journal of Climate 21: 6457-6475. DOI: 10.1175/2008JCLI2607.1.

Rodríguez-Fonseca B, Polo I, García-Serrano J, Losada T, Mohino E, Mechoso CR, Kucharski F. 2009. Are Atlantic Niños enhancing Pacific ENSO events in recent decades? Geophysical Research Letters 36: L20705. DOI: 10.1029/2009GL040048.

Rowell DP. 2003. The impact of mediterranean SSTs on the Sahelian rainfall season. Journal of Climate 16: 849-862.

Ruti PM, Dell'Aquila A. 2010. The XX century AEWs in reanalyses and IPCC simulations, from intra-seasonal to inter-annual variability. Climate Dynamics, DOI: 10.1007/s00382-010-0894-z.

Wang C, Kucharski F, Barimalala R, Bracco A. 2009. Teleconnections of the Tropical Atlatnic to the Tropical Indian and Pacific Oceans: a review of recent findings. Special Issue of Meteorologische Zeitschrift 18: 445-454. DOI: 10,1127/0941-2948/2009/0394.

Ward MN. 1998. Diagnosis and short-lead time prediction of summer rainfall in tropical North Africa at interannual and multidecadal timescales. Journal of Climate 11: 3167-3191.

Zeng N, Neelin JD, Lau KM, Tucker CJ. 1999. Enhancement of interdecadal climate variability in the Sahel by vegetation interaction. Science 286: 1537-1540. 